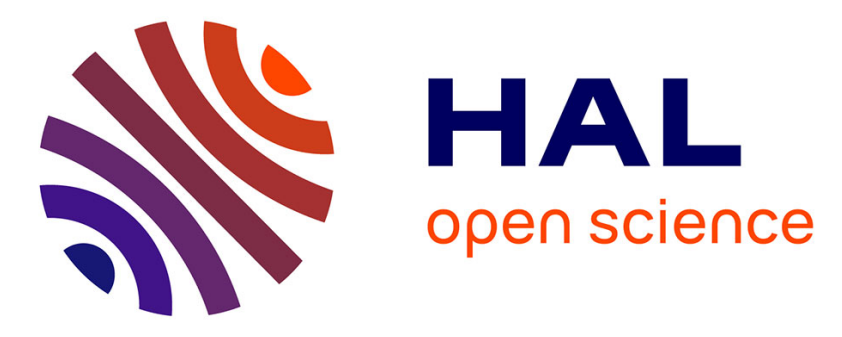

\title{
Early Diagnosis of Alzheimer's Disease Using Subject-Specific Models of FDG-PET Data
}

Ninon Burgos, Jorge Samper-González, Jorge M. Cardoso, Stanley

Durrleman, Sébastien Ourselin, Olivier Colliot

\section{- To cite this version:}

Ninon Burgos, Jorge Samper-González, Jorge M. Cardoso, Stanley Durrleman, Sébastien Ourselin, et al.. Early Diagnosis of Alzheimer's Disease Using Subject-Specific Models of FDG-PET Data. AAIC 2017 - Alzheimer's Association International Conference, Jul 2017, London, United Kingdom. pp.1-2, 10.1016/j.jalz.2017.06.1618 . hal-01621383

\section{HAL Id: hal-01621383 \\ https://hal.inria.fr/hal-01621383}

Submitted on 25 Oct 2017

HAL is a multi-disciplinary open access archive for the deposit and dissemination of scientific research documents, whether they are published or not. The documents may come from teaching and research institutions in France or abroad, or from public or private research centers.
L'archive ouverte pluridisciplinaire HAL, est destinée au dépôt et à la diffusion de documents scientifiques de niveau recherche, publiés ou non, émanant des établissements d'enseignement et de recherche français ou étrangers, des laboratoires publics ou privés. 


\title{
Early Diagnosis of Alzheimer's Disease using Subject-specific Models of FDG PET Data
}

\author{
Ninon Burgos ${ }^{1,2}$, Jorge Samper-González ${ }^{1,2}$, M. Jorge Cardoso ${ }^{3,4}$, Stanley Durrleman ${ }^{1,2}$, \\ Sébastien Ourselin ${ }^{3,4}$ and Olivier Colliot ${ }^{1,2,5}$
}

\author{
${ }^{1}$ Inria Paris, Aramis project-team, Paris, France \\ ${ }^{2}$ Sorbonne Universités, UPMC Univ Paris 06, Inserm, CNRS, Institut du Cerveau et la Moelle \\ épinière (ICM) - Pitié-Salpêtrière Hospital, Boulevard de l'hôpital, Paris, France \\ ${ }^{3}$ Translational Imaging Group, Centre for Medical Image Computing, University College London, \\ London, UK \\ ${ }^{4}$ Dementia Research Centre, Institute of Neurology, University College London, London, UK \\ ${ }^{5}$ AP-HP, Departments of Neuroradiology and Neurology, Pitié-Salpêtrière Hospital, Boulevard de \\ l'hôpital, Paris, France
}

Background: In machine learning classification methods developed for dementia studies, neuroimaging features, e.g. glucose consumption extracted from PET images, are often used to draw the border that differentiates normality from abnormality. However, these features are affected by the anatomical variability present in the population, which acts as a confounding factor making the task of finding the frontier (i.e. the decision function) between normality and abnormality very challenging.

Methods: To reduce the confounding impact of anatomical variability when trying to distinguish disease versus normal ageing, we developed a method able to extract for each individual the signal characteristic of abnormality from ${ }^{18} \mathrm{~F}$-FDG PET data. Instead of comparing the patient's PET image to a population of healthy controls as usually done, this framework consists of creating a patient-specific model of healthy PET appearance, and comparing the patient's PET image to the model via a Z-score [1]. We applied this method to 321 ADNI2 subjects (89 cognitively normal subjects amyloid negative (SUVR $<1.11$ ), and 68 early MCI, 78 late MCI and 86 Alzheimer's disease patients all amyloid positive (SUVR $>1.11)$ ). The subject-specific Z-maps generated with the proposed method were then used as features to feed a classification algorithm based on linear support vector machines (SVM). We compared the classification results obtained using the subjectspecific Z-maps to the classification results obtained using features directly obtained from the PET images, and using state-of-the-art Z-maps.

Results: The balanced accuracy obtained with the proposed method when differentiating CN from early and late MCI ( $64 \%$ and $82 \%$, respectively) was found to be higher than the balanced accuracy obtained using PET SUVR values (58\% and $75 \%$ ) and the state-of-the-art Z-maps (64\% and 78\%) as features. More detailed results are shown in Table 1.

Conclusions: Instead of trying to find the frontier between normality and abnormality at the population level, by transporting the problem to the individual level, the proposed method appears to offer a more effective way of differentiating dementia stages.

References: [1] Burgos, N. et al.: Subject-specific models for the analysis of pathological FDG PET data. In: MICCAI 2015, pp.651-658 (2015) 


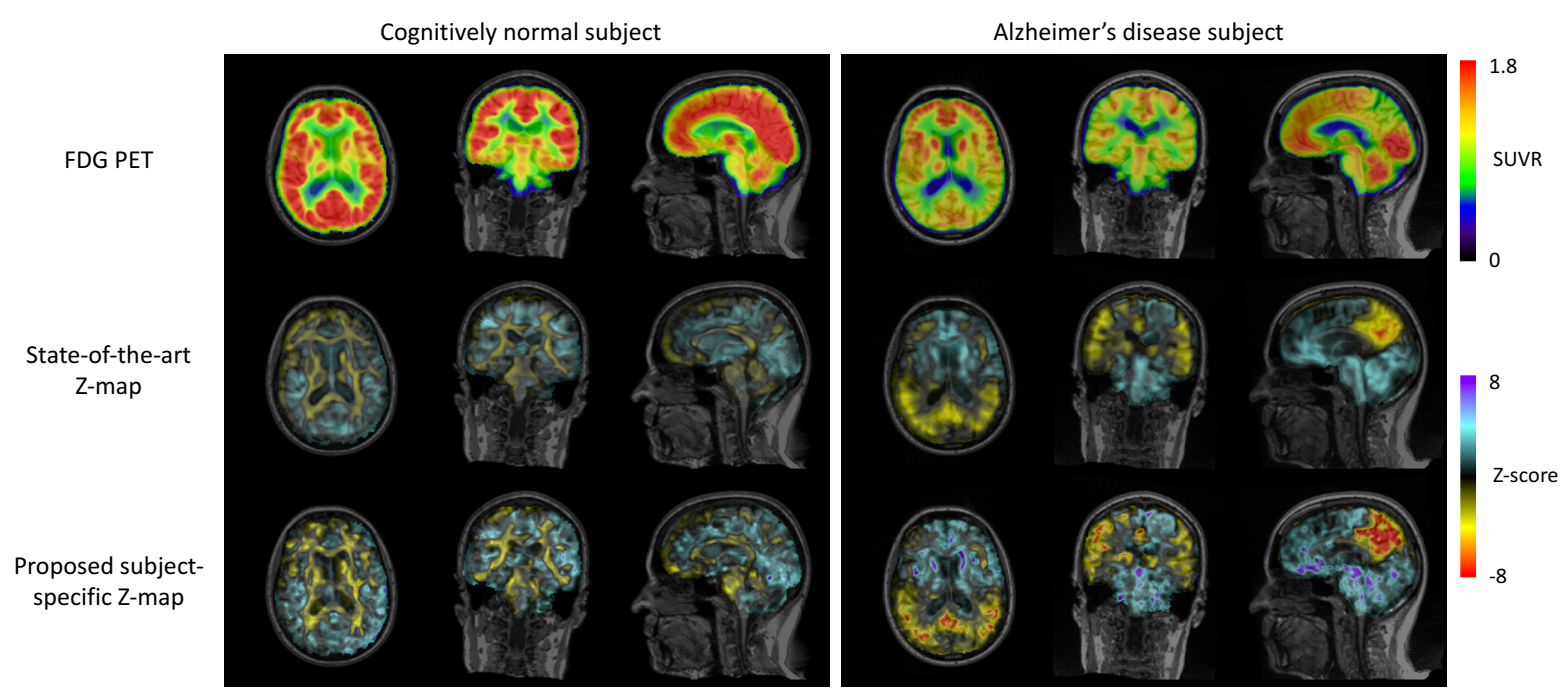

Figure 1: Examples of FDG PET, state-of-the-art Z-map and proposed subject-specific Z-map images for a cognitively normal and an Alzheimer's disease subject. Note that a negative Z-score (red) indicates a reduced FDG uptake in the subject relative to the controls.

Table 1: Balanced accuracy obtained when using PET standardised uptake value ratio (SUVR) images, state-of-the-art Z-maps (obtained by comparing the patient's PET image to a population of healthy controls), and proposed subject-specific Z-maps (obtained by comparing the patient's PET image to a subject-specific model of healthy PET appearance) as features of the linear SVM classification algorithm.

\begin{tabular}{lccc} 
& CN vs AD & CN vs LMCI & CN vs EMCI \\
\hline PET SUVR images & $93 \%$ & $75 \%$ & $58 \%$ \\
\hline State-of-the-art Z-maps & $94 \%$ & $78 \%$ & $64 \%$ \\
\hline Proposed subject-specific Z-maps & $93 \%$ & $82 \%$ & $64 \%$ \\
\hline
\end{tabular}

CN: cognitively normal - AD: Alzheimer's disease - LMCI: late mild cognitive impairment - EMCI: early mild cognitive impairment 